\title{
One stage adjustable sutures: practical aspects
}

\author{
S T Ruben, J S Elston
}

\begin{abstract}
Strabismus surgery using one stage adjustable sutures was carried out under local anaesthesia in six patients with good results. The criteria for patient selection and the surgical technique are discussed.

(BrF Ophthalmol 1992; 76: 675-677)
\end{abstract}

Since their re-introduction by Jampolsky in $1974,{ }^{1}$ adjustable suture techniques have been widely used and the indications, stability, and benefits of the technique well documented. ${ }^{2-5}$

In general, a two stage procedure is used in which the estimated amount of muscle recession or resection is performed at the time of surgery and then adjusted some time later, usually between 5 and 24 hours postoperatively. Though the one stage procedure using only topical anaesthesia is not new, ${ }^{6}$ attitudes towards the use of a single stage operation with adjustment taking place at the time of surgery have turned full circle and with the present desire to keep hospitalisation to a minimum and remove the risks associated with general anaesthesia the one stage procedure has more recently been resurrected. ${ }^{7}$ Though the outcome and stability of this technique matches that of the two stage operation, ${ }^{8}$ the practical aspects associated with the single stage operation are not well documented.

We describe our experience in six consecutive cases successfully operated on using the technique and discuss the indications and method.

\section{Patients, materials and method}

Six consecutive patients with non-concomitant strabismus underwent surgery under local anaesthesia after full informed consent. The decision to use local anaesthesia was made either on medical grounds or at the request of the patient. Of the six patients, three had squints secondary to peripheral pathology; dysthyroid eye disease (two cases), and cataract surgery, while three had central causes; internuclear ophthalmoplegia, pontine exotropia, and skew deviation. The number of muscles operated on ranged from one to four.

No predmedication was used in any of the cases. A cardiac monitor was used in every case, but there were no problems encountered from the effects of the oculocardiac reflex. Local anaesthesia consisted of topical amethocaine 1\% applied every 5 minutes for six applications prior to surgery and then continued at frequent intervals throughout the procedure. This was supplemented by subconjunctival infiltration of $0 \cdot 1-0.2 \mathrm{ml} 2 \%$ lignocaine with adrenaline 1:200 000 over the insertions of the muscles to be operated on.

The skin was cleaned with povidone iodine solution and fenestrated surgical drapes applied to allow adequate exposure. A plastic steridrape was used to keep the eyelashes away from the operative field. A lid speculum was inserted. Stay sutures of $5 / 0$ silk were put through the episclera at the limbus to allow manipulation of the eye. The conjunctiva was opened over the muscle insertion and the muscle isolated taking care not to pull directly on it. The muscle was secured using double-ended $6 / 0$ vicryl suture on a spatulated needle and knotted at each side. After the muscle had been divided from its insertion, and haemostasis secured using bipolar diathermy, the sutures were passed back through the insertion once only. The amount of recession/resection was estimated and the suture tied with a double throw and half bow knot. At this stage the lid speculum was removed and adjustments made as necessary. The position of the eyes was tested using the cover test for near and distance with the patient in the supine position using a suitable fixation target on the ceiling, together with the patient's subjective reports of single vision. The cover test was performed by the assistant so that the surgeon did not need to rescrub after each cover test. Where vertical muscles were involved the cover test was also performed in downgaze. Horizontal deviations were adjusted as far as possible towards orthophoria, whilst vertical deviations involving the inferior rectus were left slightly undercorrected so that the eyes were straight in primary and downgaze positions. This was to
The Western Ophthalmic Hospital, Marylebone Road, London NW1 5YE

S T Ruben

J S Elston

Correspondence to:

Mr S T Ruben.

Accepted for publication 22 June 1992

Table 1 Results of the six cases

\begin{tabular}{|c|c|c|c|c|c|c|c|}
\hline No & Age & Sex & Cause of squint & Pre-op orthoptics & Surgery & Post-op orthoptics & Comments \\
\hline $\begin{array}{l}1 \\
2 \\
3\end{array}$ & $\begin{array}{l}83 \\
74 \\
80\end{array}$ & $\begin{array}{l}\mathbf{F} \\
\mathbf{F} \\
\mathbf{F}\end{array}$ & $\begin{array}{l}\text { Post ECCE L+R } \\
\text { Dysthyroid } \\
\text { Dysthyroid }\end{array}$ & $\begin{array}{l}\text { L/R } 16-20 \text { PD } \\
\text { L/R 12-15 PD } \\
\text { ESO 14-30 PD } \\
\text { R/L 12-20 PD }\end{array}$ & $\begin{array}{l}\text { R. IR -4 } \\
\text { R. IR -3 } \\
\text { L. MR - max } \\
\text { L. IR }-3\end{array}$ & $\begin{array}{l}\text { Straight } \\
\text { Straight } \\
\text { ESO 8-16 PD }\end{array}$ & $\begin{array}{l}\text { Diplopia relieved } \\
\text { Diplopia relieved } \\
\text { Improved area of BSV }\end{array}$ \\
\hline 4 & 35 & M & $\begin{array}{l}\text { Bilateral INO } \\
\text { skew deviation }\end{array}$ & $\begin{array}{l}\text { EXO } 4 \text { PD } \\
\text { R/L } 12 \text { PD }\end{array}$ & L. IR - 4 & $\begin{array}{l}\text { 6 M straight } \\
1 / 3 \mathrm{M} \mathrm{min} \mathrm{L/R}\end{array}$ & $\begin{array}{l}\text { Symptomatically improved } \\
\text { INO persists }\end{array}$ \\
\hline 5 & 55 & $\mathbf{M}$ & L. INO & EXO 23-35 PD & $\begin{array}{l}\text { L. } M R+4 \\
\text { L. } L R-3\end{array}$ & $\begin{array}{l}\text { Straight in } 1^{\circ} \\
\text { position }\end{array}$ & INO persists \\
\hline 6 & 76 & $M$ & Pontine exotropia & EXO 55-65 PD & $\begin{array}{l}\mathrm{R}+\mathrm{L} M \mathrm{MR}+5 \\
\mathrm{R}+\mathrm{L} \mathrm{LR}-5\end{array}$ & Straight & Patient symptom free \\
\hline
\end{tabular}

$\mathrm{ECCE}=$ extracapsular cataract extraction; $\mathrm{PD}=$ prism dioptres; $\mathrm{IR}, \mathrm{MR}, \mathrm{LR}=$ inferior, medial, lateral rectus; $\mathrm{INO}=$ internuclear ophthalmoplegia. 
Figure 1 Preoperative Hess chart.

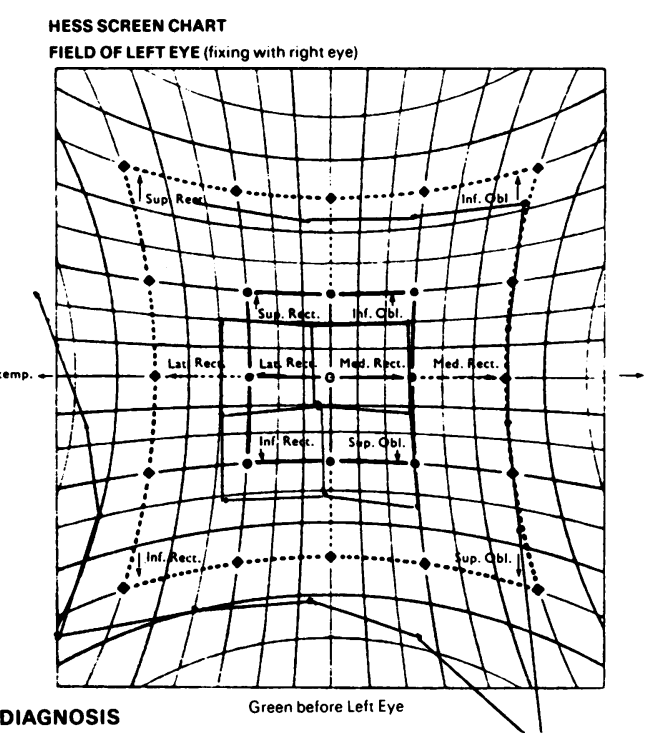

allow for the late overcorrection that can occur with inferior rectus recessions. ${ }^{9}$

\section{Results}

The results of the six cases are presented in Table 1. Follow up ranged from 3 months to 1 year. At 3 months the results had stabilised in all patients and none required further surgery.

All patients experienced discomfort of varying degrees but all were able to tolerate the procedure with little complaint. The most discomfort was associated with stretching of the rectus muscles. One patient experienced considerable postoperative pain requiring strong analgesia.

In one patient the infiltration of local anaesthetic caused subconjunctival haemorrhage which made muscle isolation more difficult and prolonged the procedure. It was also noted that at the time of adjustment the pupil of the operated eye had become significantly dilated as a result of the adrenaline.

Adjustment was difficult if attempted immediately after the operating lights had been turned off owing to bleaching of the macular pigments, and this was especially so in one patient with a degree of age-related macular
Name

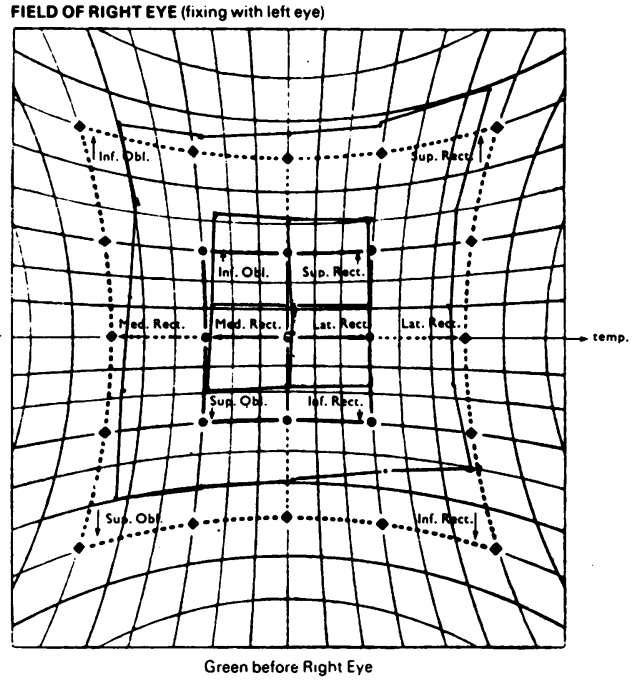

degeneration. The adjustment stage was made easier if the operating lights were angled from the side, rather than directly above, during the earlier stages of the operation.

\section{CASE REPORT}

A 35-year-old driving instructor presented with skew deviation and bilateral internuclear ophthalmoplegia following tuberculous meningitis. He had visual acuities of $6 / 6$ in both eyes and a right divergent squint with right hypertropia. Prism cover test showed the horizontal deviation to measure 10 prism dioptres (PD) for near, 25 PD distance, while the vertical deviation measured 12 PD. His complaint was of vertical diplopia and with a 12 PD Fresnel prism base down in front of the right eye he was able to obtain binocular single vision. A month later the horizontal deviation had corrected leaving the vertical deviation stable at $12 \mathrm{PD}$. $\mathrm{He}$ was admitted for surgery 6 months later as the deviation remained stable (Hess chart, Fig 1). The left inferior rectus was recessed approximately $4 \mathrm{~mm}$ and adjusted to orthophoria in the primary and downgaze positions. Four months after surgery the deviation is stable and the eyes
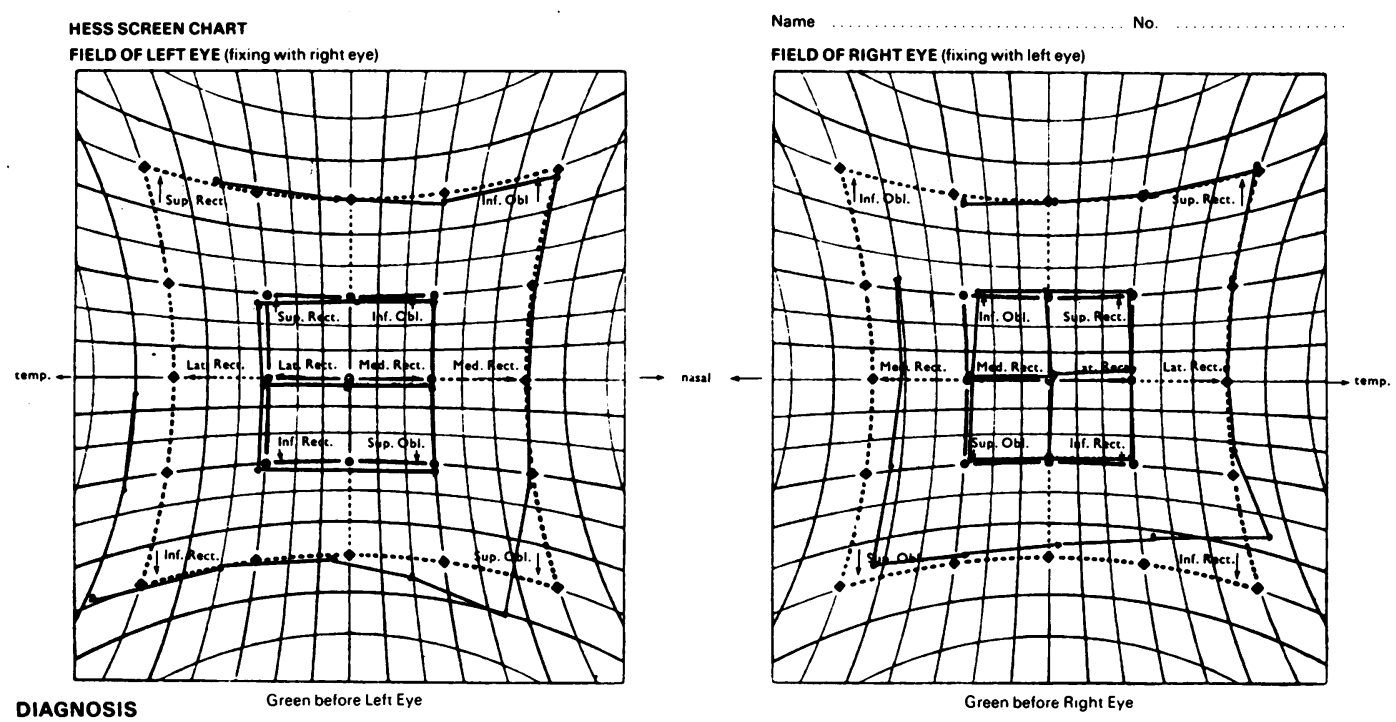
straight on cover test. However some torsional element remains and requires the use of $3 \mathrm{PD}$ prism for reading. The improvement is shown in the postoperative Hess chart (Fig 2).

\section{Discussion}

The principal indications for adjustable sutures are well documented and include most types of complicated strabismus. In this series the type of cases selected fell into two groups. Those with a localised cause, either dysthyroid eye disease or following cataract surgery, and those in which the strabismus was secondary to a central disorder of eye movement - internuclear ophthalmoplegia, skew deviation, or pontine exotropia. The results show that surgery is an effective way of treating this second group of patients providing they have a stable deviation.

The one stage procedure is particularly appropriate when general anaesthesia is contraindicated or when a patient expresses a preference for local anaesthesia. However there are limitations. The number of muscles that can be operated upon should probably be restricted to two in each eye as the patient will find surgery lasting longer than 1 hour difficult to tolerate. Eyes that have had previous surgery need special consideration as scarring may entail a difficult dissection which is likely to be time consuming and more painful.

The one stage procedure described is well tolerated by patients despite the lack of premedication. Mild hypnotics such as temazepam may have unpredictable effects and cause drowsiness which would interfere with the adjustment process. $\beta$ blockers may relieve the peripheral manifestations of anxiety, but patients may have been selected for local anaesthesia because of general medical conditions in which their use is contraindicated. The possibility that $\beta$ blockers could exacerbate the oculocardiac reflex should also be considered. The local anaesthetic described is effective on the conjunctiva and other tissues including the muscles but pulling on the muscles during resection remains unpleasant.

Postoperative pain was severe in two cases (one with four muscles operated on, one with two). This should be taken into account and adequate analgesia be made available in the postoperative period, especially if the procedure has been performed on a day surgery basis.

There are a number of problems particularly associated with one stage adjustment. There are visual factors resulting from reduced vision in the operated eye. These include a reduction in corneal clarity from corneal drying, abrasions or blood, pupillary dilatation due to adrenaline used in conjunction with the local anaesthetic, and bleaching of the macular visual pigments by the operating lights. This can be overcome by directing the lights from the side during the operation, and turning them off during the adjustment process. The distance fixation target cannot be set at 6 metres if the adjustment is done in the supine position, but this does not seem adversely to affect the outcome. The procedure is not suited for a single surgeon since a second person is needed at the adjustment stage, either a second surgeon or orthoptist. There is a possibility that the anaesthetic could alter muscle actions, though our results do not show any significant effect. This is more likely with the addition of subconjunctival anaesthesia. Finally, it is important to maintain the anaesthetic throughout the adjustment procedure.

The one stage procedure is technically difficult for the surgeon for these reasons. It is also demanding for the patient both in terms of pain and apprehension when two or more muscles are operated on, and in the difficulty of assisting the surgeon to achieve the correct suture tension owing to reduced vision in the operated eye. In conclusion, this method is suitable only for selective cases but is probably the treatment of choice for a single vertically acting muscle recession.

1 Jampolosky AL. Strabismus reoperation techniques. Trans Am Acad Ophthalmol Otolaryngol 1975; 79: 704-11.

2 Pratt-Johnson JA. Adjustable suture strabismus surgery; a review of 255 consecutive cases. Can f Ophthalmol 1985; 208: review 105 .

3 Pratt-Johnson JA. Complicated strabismus and adjustable sutures. Aust NZ F Ophthalmol 1988; 16: 87-92.

4 Franklin S, Hiatt RL. Adjustable sutures in strabismus surgery. Ann Ophthalmol 1989; 21: 285-9.

5 Lee J, O'Day J, Fells P. Early experience with adjustable squint surgery at Moorfields Eye Hospital with long term follow up. Trans Ophthalmol Soc UK 1985; 104: 662-74.

6 Thorson JC, Jampolsky A, Scott AB. Topical anaesthesia for strabismus surgery. Trans Am Ophthalmol Otolaryngol 1966; 70: $968-72$.

7 Chow PC. Stability of one stage adjustable suture for the correction of horizontal strabismus. Br f Ophthalmol 1989; 73: 541-6.

8 Fells P. Adjustable sutures. Eye 1988; 2: 33-5.

9 Wright KW. Practical aspects of the adjustable suture technique for strabismus surgery. Int Ophthalmol Clin 1989; 29: 10-5. 